\title{
The influence of special physical fitness of athletes on the level of technique of playing beach volleyball
}

\author{
Valeriy Hunchenko ${ }^{1 \mathrm{ABCDE}}$, Oleksandr Solovey ${ }^{1 \mathrm{ABCDE}}$, Dmytro Solovey ${ }^{1 \mathrm{BCDE}}$, Yaroslav Malojvan ${ }^{1 \mathrm{BCDE}}$, \\ Artem Yakovenko ${ }^{1 \mathrm{BCDE}}$, Krzysztof Wnorowski ${ }^{2 \mathrm{DE}}$ \\ ${ }^{1}$ Prydniprovska State Academy of Physical Culture and Sports, Ukraine \\ ${ }^{2}$ Gdansk University of Physical Education and Sport, Poland
}

Authors' Contribution: A - Study design; B - Data collection; C - Statistical analysis; D - Manuscript Preparation; E - Funds Collection.

\begin{tabular}{|c|c|}
\hline ct & \\
\hline $\begin{array}{l}\text { Background } \\
\text { and Study Aim }\end{array}$ & $\begin{array}{l}\text { Aim is to determine the influence of the components of special physical training on the effectiveness of } \\
\text { certain elements of the game technique during the competitive activities of beach volleyball athletes. }\end{array}$ \\
\hline $\begin{array}{l}\text { Material and } \\
\text { Methods }\end{array}$ & $\begin{array}{l}\text { The study involved athletes ( } \mathrm{n}=20 \text {, age }-17-21 \text { years, experience }-8-9 \text { years), who are engaged in beach } \\
\text { volleyball (Kherson, Ukraine). Experts ( } \mathrm{n}=5 \text {, work experience - over } 20 \text { years) from among the leading } \\
\text { volleyball specialists were involved. Training sessions were conducted according to the author's structure } \\
\text { and content of special physical training (preparatory period of the annual cycle). The author's program was } \\
\text { to increase the volume of athletic work by } 10 \% \text { (selective classes and integrated work) and } 17 \% \text { (complex } \\
\text { classes). The classes used a developed special training device. The device is designed to practice practical } \\
\text { game skills. The load at the first stage was } 70-80 \% \text { of the maximum. The load in the second stage was } 80- \\
90 \% \text { of the maximum. }\end{array}$ \\
\hline Results & $\begin{array}{l}\text { Significant }(p<0.05) \text { development of explosive power, speed and agility was revealed. There is a significant } \\
(p<0,05) \text { increase: in the number of jump serve and spike; improving the quality/number of serve and } \\
\text { attack; improving the quality of passing and the number of blocks. }\end{array}$ \\
\hline Conclusions & $\begin{array}{l}\text { The proposed structure and content of special physical training and exercises on a special simulator have } \\
\text { significantly increased the level of development of physical qualities. The athlete training program helped } \\
\text { to improve the effectiveness of certain technical actions during competitive activities. } \\
\text { competitive activity, physical qualities, jump serve, attack. }\end{array}$ \\
\hline
\end{tabular}

\section{Introduction}

The stage of preparation for higher achievements plays a crucial role in preparing athletes for the main competitions in the chosen sport. At this stage, it is expected to achieve maximum results in sports and competitions. The main tasks of the stage are the maximum use of tools that can cause a rapid adaptation processes $[1,2]$. A fundamentally important point is to ensure an important condition: the period of maximum propensity of athletes to achieve the highest results coincides with the period of intense training loads [1, 3-5]. An integral part of the process of sports improvement of athletes is special physical training $[3,6,7]$. It is believed that the process of sports training in beach volleyball is similar to classic volleyball. However, the special conditions of the competition make increased demands on physical and psychological readiness to competitive struggle [8-11]. This indicates the need to improve the process of special physical training of beach volleyball athletes.

Many studies have noted the importance of special physical training of athletes [1, 12-14]. Kostukov et al. [6] emphasize the lag in the level of training of domestic beach volleyball athletes from world standards. The authors emphasize the need to pay attention to the planning of the training process and its filling with effective content at the level of macro-, meso- and microcycles of training.

(c) Valeriy Hunchenko, Oleksandr Solovey, Dmytro Solovey,

Yaroslav Malojvan, Artem Yakovenko, Krzysztof Wnorowski, 2021 doi:10.15561/20755279.2021.0605
Balasas [15] notes that physical training and variability of technique determine the achievement of high results in competitive activities. In other studies [12, 16, 17] it is proposed to improve the modern system of sports training by increasing the amount of special training. Such approaches of the authors require a careful analysis of the results of the study.

The level of game readiness of athletes depends on the effectiveness of certain elements of the game technique in terms of responsible competitions. This determines the achievements in the international arena and their competitiveness. Analysis of the strengths and weaknesses of the training of athletes requires special attention to the technical components and physical shortcomings, which need to be addressed [16-20]. The directions of improving the training of athletes mentioned by the authors are focused on elite athletes.

Shankulov et al. [21] found that the load of athletic orientation in elite teams prevails by $10-15 \%$. Other studies [22-24] have modernized the process of training beach volleyball athletes by developing the structure and content of the annual cycle. The authors propose to increase the amount of training and competitive work, diverse use of techniques. Kostukov [6, 18] substantiates the training programs used in the physical, technical, tactical and medical-biological aspects of training beach volleyball athletes. Other authors [25-27] investigated the changes in the game that occurred due to the change in the 
rules of the game. The game has become unpredictable, competitive, spectacular due to the overall increase in active actions of athletes. Drikos et al. [28] determined the effectiveness of the elements of the game technique. The authors derived the coefficients of efficiency of service and attack (the ratio of goals won to lost). Such recommendations of the authors make it possible to plan the load depending on the individual characteristics of each athlete.

Araújo et al. [29] investigated the efficiency coefficients of different types of blocks depending on the court zones. The authors state the constant processes of adaptation in the game in attack and defense to the manner of playing the game by the opponent. Silva et al. [30] stated the fact that analytical studies in classical volleyball were comparative and prognostic. Medeiros et al. [31] have studied the analytical materials of beach volleyball games and claim a gradual transition from descriptive to comparative and prognostic. Balasas et al. [32] claim that the accentuated effect of athletic orientation for 12 weeks increases the strength of the leg muscles and the effectiveness of the jump (by 11.6\%) on hard surfaces. Lin [33] and Hunchenko [34] argue that the use of multidirectional and multifaceted serving significantly increases the effectiveness of action team. The ability to perform the following technical actions better than the previous ones leads to a significant reserve to improve the effectiveness of the game in general [3540]. Other authors [41-43] emphasize the development of accuracy through strength exercises. Such approaches of the authors indicate the need to find new approaches in the training of elite volleyball players [44-46]. Tili et al. [47], Wnorowski et al. [48] investigated the anthropometric data of the winners of games under the aegis of the FIVB before and after changes in the rules of the game and depending on the specialization. Other studies [49, 50] have shown the effectiveness of setting the ball to qualified volleyball players in competitive conditions. Such approaches are focused on supporting coaches and players to develop game strategies, exercise planning.

These studies prove the importance of physical fitness of beach volleyball athletes. The variety of approaches to improving the components of physical fitness of athletes requires consideration of specific training conditions. The fact that there are no examples of the use of training devices in the training of athletes is noteworthy. Analysis of research to improve the structure and content of special physical training of beach volleyball athletes indicates the need for further research.

The purpose of the study is to determine the impact of the components of special physical training on the effectiveness of certain elements of the game technique during the competitive activities of beach volleyball athletes.

\section{Material and methods}

Participants. The study involved athletes $(\mathrm{n}=20$, age - 17-21 years, experience - 8-9 years), who are engaged in beach volleyball (Kherson, Ukraine). All participants gave written consent to participate in the experiment. Athletes were evaluated by 5 experts (coaches with more than 20 years of experience). According to the video of the game, they distributed technical actions according to the quality of execution (high, medium, low levels).

Organization of the study. The study was conducted on the basis of Kherson State University (Kherson, Ukraine), sports school № 6 (Kherson, Ukraine). The pedagogical experiment was conducted in two stages. At the first stage (December 2018 - April 2019) included the preparatory period of the annual cycle. It consisted of conducting the training process according to the program of the sports school [51]. The program of sports school on beach volleyball provides: theoretical (42 hours); physical (358 hours, including general - 100 hours and special physical - 258 hours); technical (398 hours); tactical (510 hours); psychological and competitive training (200 hours); testing (28 hours); pedagogical reserve (128 hours).

The second stage was held from December 2019 to March 2020. It consisted of conducting classes on the author's structure and content of special physical training of athletes (preparatory period of the annual cycle). The author's program was to increase the volume of athletic work by $10 \%$ (selective classes and integrated work) and $17 \%$ (complex classes). The increase was due to the use of pedagogical reserve time. The classes used a developed special training device. The device is designed to practice practical skills of the game [52]. 704 hours (32 hours per week) were allocated for the training process during the training period. The load at the first stage of the experiment was $70-80 \%$ of the maximum, at the second $80-90 \%$ of the maximum.

At the end of each stage, the control of special physical fitness was carried out according to the control tests: 30 meter sprint test (s); running in place (10s; number of steps); $4 \times 10$ meter Shuttle run (s); "92 m running with changing direction" test (s) (fig. 1); running $400 \mathrm{~m}$ (min, $\mathrm{s}$ ); long jump (cm); attack jump test, cm (maximum vertical jump with run up approach); overhead medicine ball $(2 \mathrm{~kg})$ throw $(\mathrm{cm})$; handgrip strength test - right and left hand (kg); Pull-Up Bars (quantity of times) [32].

The games of the Championship of Ukraine (U21) and the open championship of Kherson State University in beach volleyball (Kherson, Ukraine) were videotaped. Recording was conducted only for athletes who participated in the experiment. The method of expert evaluation of athletes' actions on the basis of video recordings was used. Five experts (trainers with more than 20 years of experience) were involved. The analysis of performance of separate elements of beach volleyball techniques in competitive conditions (quantitative and qualitative indicators, with a gradation of quality of performance - high, average and low) was carried out.

Statistical analysis. We used the program Microsoft Excel 2007. Determined the arithmetic mean, standard deviation, reliability coefficients. The coefficients of efficiency of each technical action in competitive conditions and correlation coefficients of tests of special physical training and elements of game technique were 


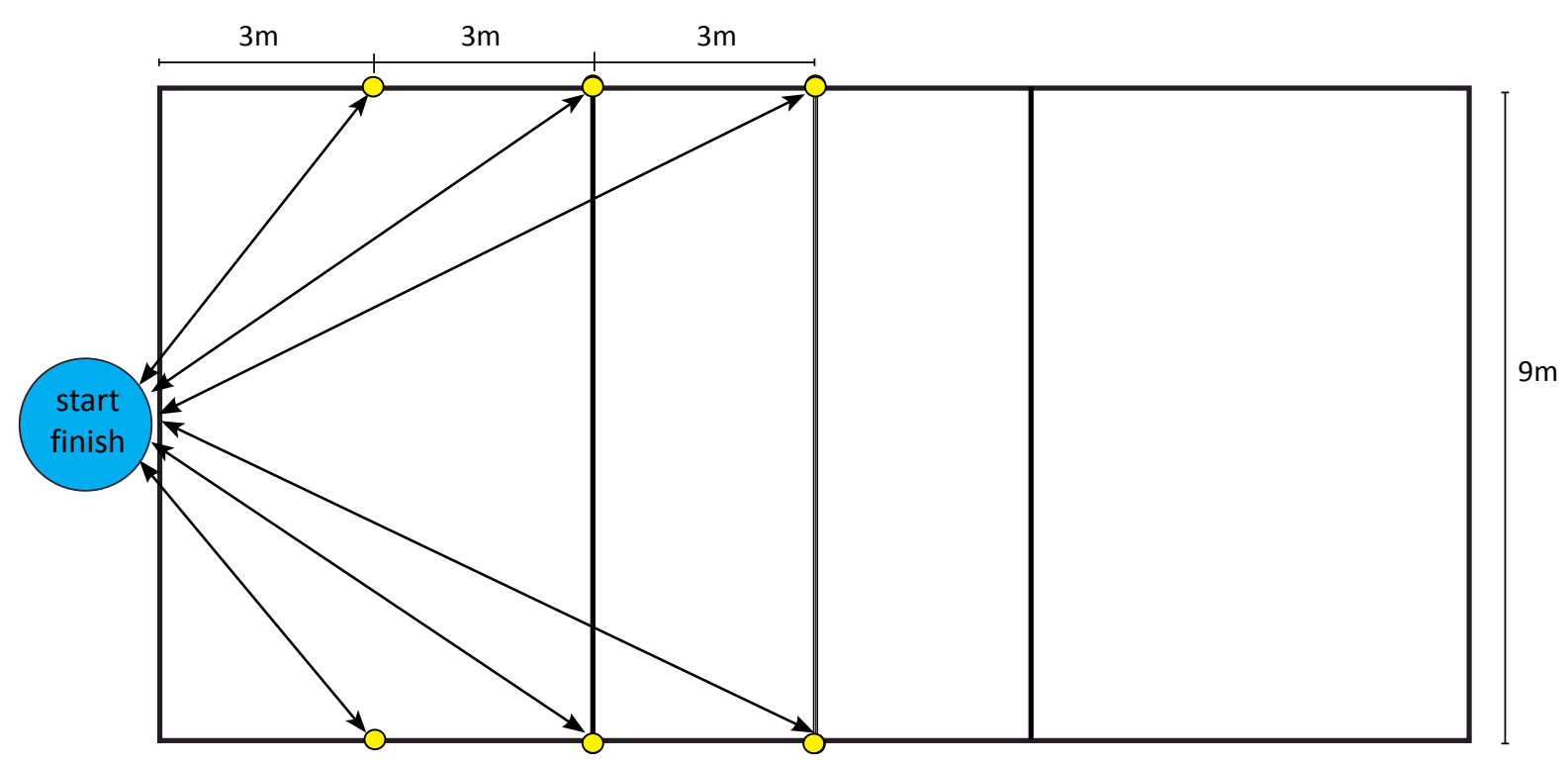

Figure 1. Test “92 m running with changing direction” (scheme)

also determined. Statistical significance was established at $\mathrm{p}<0.05$.

\section{Results}

The opinions of the experts on each of the technical actions were sufficiently consistent. The coefficients of variation range from $8.15 \%$ to $12.47 \%$. Since $V \leq 15 \%$, the opinions are consistent, the set is homogeneous and the results can be trusted.

Table 1 shows the average indicators of special physical training of athletes in the first and second stages of the experiment.

At the end of the pedagogical experiment, the average indicators of special physical fitness of athletes indicate the following: the rate of speed abilities corresponds to the level of assessment of "good"; speed of movement - a high level; dexterity - "excellent"; endurance "satisfactory"; explosive force - "excellent"; explosive strength of the muscles of the torso and arms - "excellent"; arm flexor strength - "satisfactory"; handgrip strength test (dynamometry of the right and left arm) - the average level of physical development.

The analysis of indicators (Table 1) shows that the developed and implemented structure and content of special physical training of athletes contributed to a significant reliable $(p<0.05)$ development of the explosive force of the extensor muscles. The speed also experienced a significant $(p<0.05)$ increase. The strength of the flexor muscles of the upper extremities has significant $(p<0.05)$ differences at the lower limit of the representativeness error. The strength of the muscles of the torso and extensors of the arms outweigh the similar indicators of the first stage. The differences are statistically significant $(p<0.05)$. The proposed structure and content of special physical training of athletes fully contributed to the development of flexor muscles of athletes' limbs. Indicators of arm and leg flexor muscles do not have significant dynamics of improvement: the changes are significant $(\mathrm{p}<0.05)$, but their result has changed from the level of evaluation "unsatisfactory" to the level of evaluation "satisfactory".

Table 2 shows the indicators of attacking actions of athletes in competitive conditions in the first and second stages of the experiment. Analysis of attack performance indicators (Table 2) indicates the presence of significant $(\mathrm{p}<0.05)$ differences in technical performance indicators. The quantitative indicator of serving strategy (1. Serving high, placing the ball short; 2 . Serving high, placing the ball deep; 3 . Serving low, placing the ball short; 4. Serving low, placing the ball deep) performance has decreased. However, the indicator did not reach the appropriate level of reliability $(\mathrm{p}>0.05)$.

Table 3 shows the indicators of action in defense. Analysis of performance indicators in defense in competitive conditions indicates the presence of significant differences (Table 3). Thus, the rate of quality of reception has increased significantly. This indicates a significant improvement in the efficiency of this technical action. Quantitative and qualitative indicators of the game in defense has increased slightly. However, the changes did not reach the appropriate level of reliability ( $p>0.05)$.

Table 4 shows the coefficients of effectiveness of action in the attack of athletes in competitive conditions in the first and second stages of the experiment. This ratio was calculated by the ratio of successful actions (high level of performance) to all actions from a particular element of the game technique. Analysis of the effectiveness of game actions in the attack (Table 4) shows that most indicators of technical action have increased significantly. It is established that most of the indicators of efficiency of the performed technical actions at the second stage of the experiment improved in relation to the first. The jump serve efficiency indicator improved by 0.03 units. It should also be noted the significant increase in goals scored due to this technical action. At the same time, the efficiency of tactical delivery has an increase. Passing efficiency increased by 0.1 units. 
Table 1. Average indicators of special physical training of athletes in the first and second stages of the experiment (n = 20)

\begin{tabular}{|c|c|c|c|c|c|c|}
\hline \multirow{3}{*}{ Tests } & \multicolumn{6}{|c|}{ Statistical indicators } \\
\hline & \multicolumn{2}{|c|}{$\begin{array}{l}\text { First stage of the } \\
\text { experiment }(n=20)\end{array}$} & \multicolumn{4}{|c|}{ Second stage of the experiment $(n=20)$} \\
\hline & $\bar{x}$ & $\mathbf{S}$ & $\bar{x}$ & $\mathbf{S}$ & $\mathbf{t}$ & $\mathbf{p}$ \\
\hline 30 meter sprint test $(\mathrm{s})$ & 4.51 & 0.19 & 4.0 & 0.08 & -10.59 & $<0.05$ \\
\hline Running in place (10s.; number of steps) & 67.05 & 5.37 & 72.3 & 4.64 & 3.23 & $<0.05$ \\
\hline $4 \times 10$ meter Shuttle run (s) & 6.74 & 0.22 & 6.51 & 0.07 & -4.29 & $<0.05$ \\
\hline “92 m running with changing direction" test (s) & 24.37 & 0.86 & 23.39 & 0.79 & -3.66 & $<0.05$ \\
\hline Running $400 \mathrm{~m}$ (min, s) & 1.1 & 0.11 & 1.0 & 0.52 & -1.96 & $>0.05$ \\
\hline Long jump $(\mathrm{cm})$ & 264 & 0.16 & 296 & 0.06 & 8.19 & $<0.05$ \\
\hline Attack jump test $(\mathrm{cm})$ & 66.75 & 5.32 & 84.7 & 2.74 & 13.8 & $<0.05$ \\
\hline Overhead medicine ball $(2 \mathrm{~kg})$ throw $(\mathrm{cm})$ & 821 & 0.45 & 864 & 0.32 & 3.42 & $<0.05$ \\
\hline Handgrip strength test, right hand ( $\mathrm{kg}$ ) & 43.85 & 13.61 & 50.2 & 11.69 & 1.54 & $>0.05$ \\
\hline Handgrip strength test, left hand (kg) & 38.45 & 15.08 & 47.3 & 12.5 & 1.97 & $>0.05$ \\
\hline Pull-Up Bars (number) & 10.4 & 3.83 & 13.0 & 3.38 & 2.27 & $<0.05$ \\
\hline
\end{tabular}

Table 2. Indicators of attacking actions of athletes in the first and second stages of the experiment $(n=20)$

\begin{tabular}{|c|c|c|c|c|c|c|c|c|}
\hline \multirow[t]{2}{*}{ № } & \multirow{2}{*}{ Technical actions } & \multicolumn{2}{|c|}{$\begin{array}{l}\text { First stage of the } \\
\text { experiment }\end{array}$} & \multicolumn{2}{|c|}{$\begin{array}{l}\text { Second stage of the } \\
\text { experiment }\end{array}$} & \multirow[t]{2}{*}{$\Delta \mathbf{x}$} & \multirow{2}{*}{$\mathbf{t}$} & \multirow{2}{*}{$\mathbf{p}$} \\
\hline & & $\bar{x}$ & $\mathrm{~s}$ & $\bar{x}$ & $\mathbf{s}$ & & & \\
\hline \multirow{2}{*}{1} & Number of jump serve & 1.05 & 1.05 & 4.5 & 2.48 & 2.09 & 5.58 & $<0.05$ \\
\hline & High level of jump serves & 0.4 & 0.68 & 1.85 & 1.13 & 2.09 & 4.77 & $<0.05$ \\
\hline \multirow{2}{*}{2} & Number of tactical serves & 21.6 & 3.6 & 19.2 & 3.65 & 2.09 & -1.78 & $>0.05$ \\
\hline & High level of serve & 6.0 & 7.36 & 8.4 & 2.5 & 2.09 & 1.34 & $>0.05$ \\
\hline \multirow{2}{*}{3} & Number of settings & 19.05 & 9.6 & 19.35 & 8.85 & 2.09 & 0.1 & $>0.05$ \\
\hline & High level of settings & 13.5 & 9.58 & 16.15 & 8.82 & 2.09 & 0.89 & $>0.05$ \\
\hline \multirow{2}{*}{4} & Number of tactical attacks & 15.4 & 7.98 & 12.6 & 5.69 & 2.09 & -1.25 & $>0.05$ \\
\hline & High level of tactical attacks & 4.35 & 3.34 & 6.75 & 2.36 & 2.09 & 2.56 & $<0.05$ \\
\hline \multirow{2}{*}{5} & Number of attacks & 6.9 & 4.76 & 13.5 & 2.95 & 2.09 & 5.14 & $<0.05$ \\
\hline & High level of attack & 3.95 & 3.69 & 8.1 & 1.33 & 2.09 & 4.61 & $<0.05$ \\
\hline
\end{tabular}

Table 3. Indicators of protective actions of athletes in the first and second stages of the experiment $(n=20)$

\begin{tabular}{|c|c|c|c|c|c|c|c|c|}
\hline \multirow[t]{2}{*}{ № } & \multirow[t]{2}{*}{ Technical actions } & \multicolumn{2}{|c|}{$\begin{array}{l}\text { First stage of } \\
\text { the experiment }\end{array}$} & \multicolumn{2}{|c|}{$\begin{array}{l}\text { Second } \\
\text { stage of the } \\
\text { experiment }\end{array}$} & \multirow[t]{2}{*}{$\Delta \mathbf{x}$} & \multirow[t]{2}{*}{$\mathbf{t}$} & \multirow[t]{2}{*}{$\mathbf{p}$} \\
\hline & & $\bar{x}$ & S & $\bar{x}$ & $\mathbf{s}$ & & & \\
\hline \multirow[t]{2}{*}{1} & $\begin{array}{l}\text { Number of passing (the forearm pass, overhead } \\
\text { passing) }\end{array}$ & 22.55 & 9.25 & 23.35 & 7.47 & 2.09 & 0.66 & $>0.05$ \\
\hline & $\begin{array}{l}\text { High level of passing (the forearm pass, } \\
\text { overhead passing) }\end{array}$ & 14.9 & 9.07 & 19.55 & 6.58 & 2.09 & 2.10 & $<0.05$ \\
\hline \multirow[t]{2}{*}{2} & Number of technical actions in defense & 15.9 & 10.26 & 16.85 & 9.21 & 2.09 & 0.30 & $>0.05$ \\
\hline & High level of technical actions in defense & 8.15 & 5.07 & 11.25 & 5.44 & 2.09 & 1.82 & $>0.05$ \\
\hline \multirow[t]{2}{*}{3} & Number of technical actions blocks & 12.75 & 18.32 & 18.35 & 16.86 & 2.09 & 0.98 & $>0.05$ \\
\hline & High level of technical actions blocks & 2.35 & 2.92 & 7.05 & 5.53 & 2.09 & 3.27 & $<0.05$ \\
\hline
\end{tabular}


Table 4. Coefficients of effectiveness of action in the attack in the first and second stages of the experiment $(n=20)$

\begin{tabular}{llllll}
\hline \multirow{2}{*}{ Stage of the experiment } & \multicolumn{2}{l}{ Attack Actions } & & & \\
\cline { 2 - 6 } & Jump serve & Tactical serve & Setting & Attack & Tactical attack \\
\hline First & 0.38 & 0.31 & 0.71 & 0.57 & 0.28 \\
Second & 0.41 & 0.49 & 0.84 & 0.6 & 0.54 \\
\hline
\end{tabular}

Table 5. Coefficients of effectiveness of actions in defense at the first and second stages of experiment $(n=20)$

\begin{tabular}{llll}
\hline \multirow{2}{*}{ Stage of the experiment } & \multicolumn{2}{l}{ Defense Actions } & Blocking \\
\hline First & Passing & Game in defense & 0.18 \\
Second & 0.66 & 0.51 & 0.38 \\
\hline
\end{tabular}

Table 6. Correlation coefficients between indicators of special physical fitness and indicators of action in the attack of athletes before and after the second stage of the experiment $(n=20)$

\begin{tabular}{|c|c|c|c|c|c|c|c|c|c|c|c|c|c|}
\hline $\begin{array}{l}\text { Tests/indicators of } \\
\text { game technics }\end{array}$ & 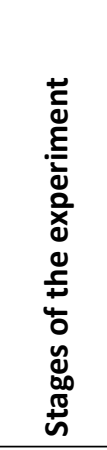 & 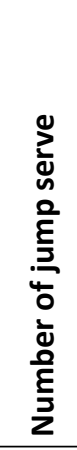 & 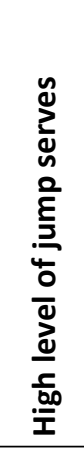 & 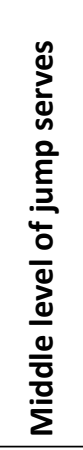 & 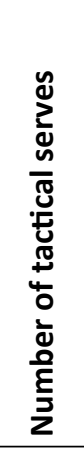 & 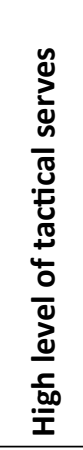 & 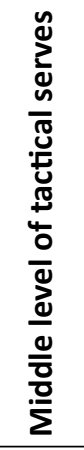 & 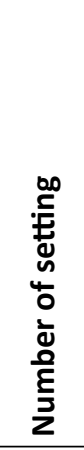 & 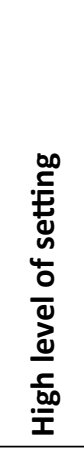 & 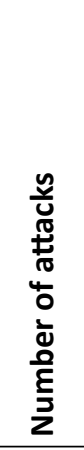 & 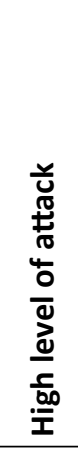 & 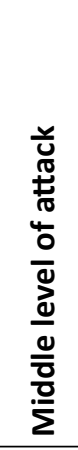 & 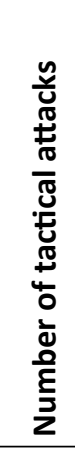 \\
\hline Tests & & \multicolumn{12}{|c|}{ Correlation coefficients between indicators } \\
\hline \multirow{2}{*}{$\begin{array}{l}30 \text { meter sprint test } \\
\text { (s) }\end{array}$} & before & 0.10 & 0.37 & -0.10 & -0.10 & 0.13 & 0.12 & -0.07 & 0.04 & 0.41 & 0.29 & 0.23 & 0.03 \\
\hline & after & 0.37 & 0.32 & 0.20 & 0.06 & -0.13 & 0.29 & 0.19 & 0.27 & 0.43 & 0.36 & 0.41 & $-0,23$ \\
\hline \multirow{2}{*}{$\begin{array}{l}\text { Running in place } \\
\text { (10s.; number of } \\
\text { steps) }\end{array}$} & before & -0.10 & -0.35 & 0.20 & 0.34 & 0.3 & -0.17 & 0.19 & 0.27 & -0.01 & 0.22 & -0.43 & 0.06 \\
\hline & after & 0.14 & 0.05 & 0.31 & 0.29 & 0.29 & 0.15 & 0.32 & 0.36 & -0.23 & -0.11 & -0.22 & 0.05 \\
\hline \multirow{2}{*}{$\begin{array}{l}4 \times 10 \text { meter Shuttle } \\
\text { run }(s)\end{array}$} & before & -0.48 & -0.34 & -0.58 & -0.05 & 0.22 & -0.35 & 0.32 & 0.22 & 0.13 & 0.15 & 0.25 & -0.10 \\
\hline & after & -0.46 & -0.25 & -0.54 & -0.24 & -0.15 & -0.19 & 0.25 & -0.04 & 0.26 & 0.20 & 0.11 & -0.21 \\
\hline \multirow{2}{*}{$\begin{array}{l}\text { "92 m running with } \\
\text { changing direction" } \\
\text { test (s) }\end{array}$} & before & -0.31 & 0.01 & -0.61 & -0.29 & 0.26 & -0.42 & 0.3 & 0.09 & 0.26 & 0.27 & 0.21 & -0.41 \\
\hline & after & -0.39 & 21 & -0.60 & -0.13 & 0.03 & -0.34 & 0.17 & -0.09 & 0.27 & 0.25 & 0.29 & -0.3 \\
\hline \multirow{2}{*}{ Long jump (cm) } & before & 0 & 0 & 0.01 & + & 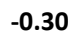 & -0.25 & 0.25 & 0.45 & 0.41 & 0.42 & -0.01 & -0.44 \\
\hline & after & 0.60 & 0.57 & 0.50 & -0.27 & -0.35 & 0.18 & 0.53 & 0.52 & 0.4 & 0.37 & -0.22 & -0.48 \\
\hline \multirow{2}{*}{$\begin{array}{l}\text { Attack jump test } \\
(\mathrm{cm})\end{array}$} & before & 0. & 0.1 & 0.55 & -0.05 & -0.16 & 0.1 & -0.27 & -0.18 & 0.31 & 0.44 & 0. & -0.31 \\
\hline & after & 0.49 & 0.27 & 0.50 & -0.1 & 0.03 & -0.03 & -0.26 & -0.24 & 0.51 & 0.48 & 0.28 & -0.27 \\
\hline \multirow{2}{*}{$\begin{array}{l}\text { Overhead medicine } \\
\text { ball }(2 \mathrm{~kg}) \text { throw } \\
(\mathrm{cm})\end{array}$} & b & 0. & . & 0.08 & -0.03 & 0.06 & -0.15 & 0.38 & 0.30 & 0.11 & 0.21 & -0.12 & -0.17 \\
\hline & after & 0.26 & 0.23 & 0.22 & -0.29 & -0.17 & -0.13 & 0.52 & 0.43 & 0.14 & 0.21 & -0.28 & -0.32 \\
\hline \multirow{2}{*}{$\begin{array}{l}\text { Pull-Up Bars } \\
\text { (number) }\end{array}$} & 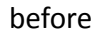 & 0.36 & -0.07 & 0.35 & 0.31 & 0.24 & 0.16 & 0.17 & 0.40 & 0.36 & 0.48 & -0.23 & 0.22 \\
\hline & after & 0.38 & 0.22 & 0.55 & 0.21 & 0.29 & 0.25 & 0.18 & 0.33 & 0.30 & 0.38 & -0.34 & -0.03 \\
\hline
\end{tabular}


Table 5 shows the coefficients of effectiveness of actions in defense in competitive conditions in the first and second stages of the experiment. The analysis of indicators indicates that the effectiveness of actions in the second stage of the experiment exceeds the performance indicators of the first stage. In particular, the efficiency of passing and blocking prevails by 0.2 units, and in defense - by 0.16 units. Blocking is the most difficult and effective means of defense. This indicates a significant increase in the overall effectiveness of gaming in competitive conditions.

Table 6 shows the correlation coefficients between the indicators of special physical fitness and action in the attack of athletes (competitive conditions in the first and second stages of the experiment). In most cases, we note a slight increase in the coefficients after the second stage of the experiment (Table 6).

Table 7 shows the correlation coefficients between indicators of special physical fitness and quantitative and qualitative indicators of actions in the protection of athletes in competitive conditions. The data of the relationship between the studied components of protection in the test " 30 meter sprint test (s)" had a positive effect on the performance of blocks. There is a negative relationship with the indicators of reception and play in defense. The "Running in place (10s.; number of steps)" test confirms a positive relationship with blocking (direct correlation) and a negative relationship with defensive performance.

The proposed experimental structure and content of special physical training of athletes contributed to a significant increase in the strength of the muscles of the extensors of the arms, thighs and legs. On this basis, they contributed to the development of explosive power. This had a real impact on the performance of competitive activities in technical actions with the manifestation of explosive force: jump serve, attack, blocking.

The obtained reliable data $(p<0.05)$ changes in the indicators of explosive force, dexterity and strength of extensor muscles contributed to more drastic changes in the indicators of action in defense in competitive conditions. This trend was observed by us in previous studies [34-36].

The general trend of the relationship between the leading physical qualities and the level of performance of certain techniques of the game technique indicates the quality of performance of the elements of the game technique in the attack. The quality of performance of the elements of the technique of play in defense depends

Table 7. Correlation coefficients between indicators of special physical fitness and indicators of action in the defense of athletes before and after the second stage of the experiment $(n=20)$

Tests/indicators of game technique
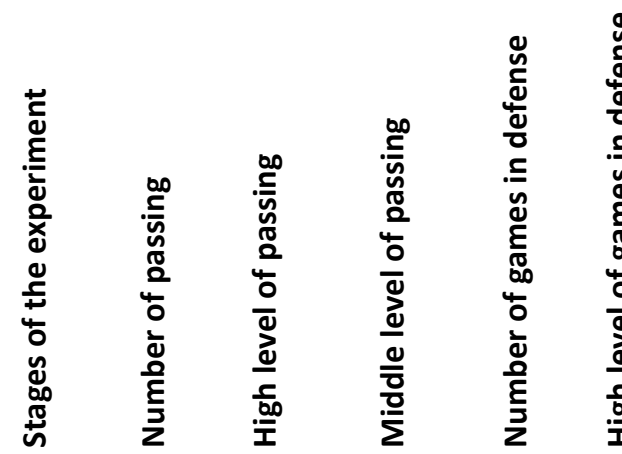
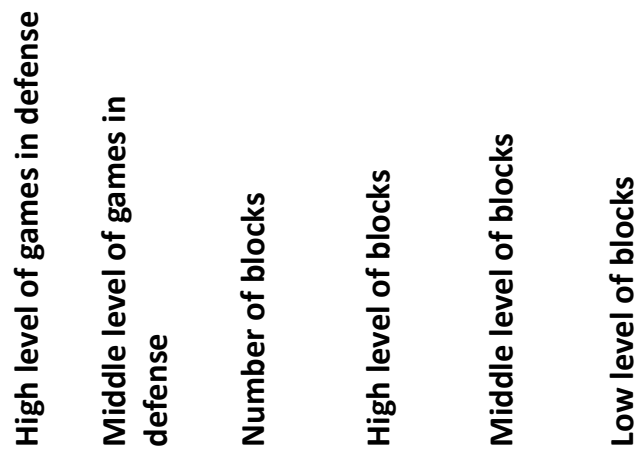

\begin{tabular}{|c|c|c|c|c|c|c|c|c|c|c|c|}
\hline \multirow{3}{*}{$\begin{array}{l}\text { Tests } \\
30 \text { meter sprint test }(\mathrm{s})\end{array}$} & \multirow{3}{*}{$\begin{array}{l}\text { before } \\
\text { after }\end{array}$} & \multicolumn{10}{|c|}{ Correlation coefficients between indicators } \\
\hline & & 0.31 & 0.24 & 0.19 & 0.49 & 0.47 & 0.12 & -0.22 & -0.39 & -0.06 & -0.3 \\
\hline & & 0.41 & 0.37 & 0.48 & 0.49 & 0.48 & 0.16 & -0.31 & -0.34 & -0.12 & -0.37 \\
\hline \multirow{2}{*}{$\begin{array}{l}\text { Running in place (10s.; } \\
\text { number of steps) }\end{array}$} & before & 0.17 & 0.24 & -0.01 & -0.36 & -0.32 & -0.13 & 0.39 & 0.3 & 0.35 & 0.43 \\
\hline & after & 0.18 & 0.20 & 0.26 & -0.35 & -0.31 & 0.02 & 0.37 & 0.41 & 0.26 & 0.43 \\
\hline \multirow{2}{*}{$\begin{array}{l}4 \times 10 \text { meter Shuttle } \\
\text { run (s) }\end{array}$} & before & 0.24 & 0.06 & 0.39 & -0.07 & -0.07 & -0.32 & 0.14 & 0.1 & 0.2 & 0.08 \\
\hline & after & 0.15 & 0.05 & 0.48 & 0.06 & -0.09 & -0.31 & 0.03 & -0.05 & 0.1 & 0.06 \\
\hline \multirow{2}{*}{$\begin{array}{l}\text { "92 m running with } \\
\text { changing direction" } \\
\text { test (s) }\end{array}$} & before & 0.31 & 0.05 & 0.49 & -0.01 & -0.02 & -0.4 & 0.19 & -0.04 & 0.29 & 0.17 \\
\hline & after & 0.34 & 0.23 & 0.49 & 0.13 & 0.01 & -0.43 & 0.11 & -0.05 & 0.12 & -0.02 \\
\hline \multirow{2}{*}{ Long jump (cm) } & before & -0.03 & 0.15 & -0.13 & -0.55 & -0.61 & -0.33 & 0.3 & 0.33 & 0.22 & 0.33 \\
\hline & after & 0.22 & -0.38 & -0.32 & -0.61 & -0.64 & -0.33 & 0.59 & 0.66 & 0.48 & 0.59 \\
\hline \multirow{2}{*}{ Attack jump test $(\mathrm{cm})$} & before & -0.25 & -0.01 & -0.57 & -0.25 & -0.18 & -0.47 & 0.22 & 0.26 & 0.13 & 0.29 \\
\hline & after & -0.56 & -0.41 & -0.36 & -0.13 & -0.16 & -0.31 & 0.25 & 0.24 & 0.12 & 0.27 \\
\hline \multirow{2}{*}{$\begin{array}{l}\text { Overhead medicine } \\
\text { ball }(2 \mathrm{~kg}) \text { throw }(\mathrm{cm})\end{array}$} & before & -0.42 & -0.42 & -0.15 & -0.41 & -0.42 & 0.1 & 0.23 & 0.42 & 0.17 & 0.29 \\
\hline & after & -0.36 & -0.31 & -0.11 & -0.58 & -0.61 & -0.1 & 0.46 & 0.54 & 0.32 & 0.41 \\
\hline \multirow{2}{*}{ Pull-Up Bars (number) } & before & 0.23 & 0.27 & -0.03 & 0.34 & 0.41 & 0.13 & 0.06 & -0.01 & 0.09 & 0.05 \\
\hline & after & 0.2 & 0.21 & 0.11 & 0.31 & 0.27 & 0.17 & 0.21 & 0.19 & 0.18 & 0.2 \\
\hline
\end{tabular}


on the level of development of the strength of the flexor muscles of the upper and lower extremities.

\section{Discussion}

Beach volleyball is currently developing rapidly in the world. Scientists note that recently the game has undergone significant changes in connection with the objective process of game development, as well as significant changes in the rules of the competition $[18$, 25-27]. In recent years, issues related to the construction of the training process in classical and beach volleyball have been studied in detail $[19,23,24]$. Today, there are not enough studies that reveal the structure and content of special physical training of beach volleyball athletes. The aim of the study was to determine the impact of the components of special physical training on the effectiveness of certain elements of the game technique during the competitive activities of beach volleyball athletes.

The level of manifestation of leading physical qualities in the chosen sport plays one of the leading roles in the realization of individual potential of athletes in competitive conditions. In comparison with the data of the first and second stages of the experiment, we observe a significant $(p<0.05)$ improvement in the level of explosive force. It is manifested in the shortest possible time in competitive activities (strikes of force and tactical nature in the attack and blocking). This is evidenced by the indicators of the tests "Long jump, cm" and "Attack jump test, $\mathrm{cm}$ "). The indicators obtained by us complement and confirm the opinion of scientists [25, 32, 33, 37]. The authors note that the special physical training of athletes in the training process fully promotes the development of extensor muscles in the knee joint and ankle joint. This affects the explosive force when performing jumps for tactical strikes and blocks. Training on sandy areas toose soit requires more effort than indoors.

The use of integrated exercises in conditions of time deficit significantly $(\mathrm{p}<0.05)$ had an impact on improving dexterity in the tests " $4 \times 10$ meter Shuttle run, $\mathrm{s}$ " and "“92 m running with changing direction" test). At the end of the second stage of the experiment, we observe a significant $(\mathrm{p}<0.05)$ improvement in speed and movement rate of athletes. Test results " 30 meter sprint test, s" and "Running in place (10s.; number of steps)" indicate this. Analysis and comparison of the obtained data with the results of other studies allows us to state that special physical training and variability of technique cause positive changes in the results of competitive activities. This conclusion confirms the data available in the literature of other authors $[6,15,16.21]$.

The use of a well-founded author's program of special physical training of athletes contributed to a significant $(\mathrm{p}<0.05)$ improvement of competitive activity indicators: quantity and quality of serving floaters and jump serves; quality of serving (the forearm pass, overhead passing); quantity and quality of blocking. This is due to the fact that most serving (serving floaters and jump serves) complicate the defensive actions of their opponents.
Confirmation of our positions are the results of other studies $[9,21,30,34]$. The authors note that in such cases this leads to a winning win.

The coefficients of effectiveness of game actions in attack and defense at the end of the experiment significantly $(p<0,05)$ increased. It should be noted the increase in the efficiency of jump serves by 0.03 and setting - by 0.13 units. We also note an increase in the number of goals scored and spike by 0.03 units, soft spike - by 0.26 , passing - by 0.18 and the number of blocks by 0.2 units. Drikos et al. [28], Araújo et al. [29] suggest that there is a significant relationship between attack effectiveness and set outcome. Teams that win a set make fewer mistakes and are more effective in attacking. There is an increase in the effectiveness of technical actions in attack and defense, depending on the level of preparedness of the team.

The high level of speed qualities of athletes positively $(\mathrm{p}<0.05)$ contributed to the improvement of tactical and power strikes and blocking. It should be noted that the agility of athletes significantly $(p<0.05)$ affected the performance of jump serves, soft spike (half-speed shot, off-speed shot, change of pace) and passing. Also, we note that explosive force positively increased technical actions of force and tactical character, passing and blocking. This means that attacking and defensive skills are related to the agility, strength and speed abilities of athletes. Silva et al. [30], Tili et al. [47] show that athletes in the game make mistakes in attack and defense. Athletes' mistakes determine the effectiveness of the match (win / lose). In this context, improving the effectiveness of game activities should be a priority in the training process at the level of improving the development of leading physical qualities. It is necessary to use in the preparation of attackers and blockers the most common in practice game situations and effective solutions to game problems [30, 47].

Our research is a confirmation that the author's program of special physical training of athletes contributed to the development of physical qualities and variability of the game technique. The structure and content provided for the redistribution of hours of pedagogical reserve for selective and comprehensive classes. The training sessions used a developed training device to practice practical ball skills. Indicators of special physical fitness of beach volleyball athletes have a positive effect on the effectiveness of the elements of the technique of the game in competitive conditions. Our data complements and expands the available information on the content of the training period for team sports athletes.

\section{Conclusions}

The positive influence of the components of special physical training on the effectiveness of certain elements of the game technique during the competitive activity of athletes is determined. The experiment was based on: a sound structure and content of special physical training of athletes; author's simulator. It is recommended to take into account that strength abilities, speed qualities and dexterity significantly improve the game actions in attack 
(both jump and tactical serves and attacks, passing) and defense (digs and blocks). The obtained data complement and confirm new approaches to improving the level of special physical fitness of athletes, which affects the results of their competitive activities.

The revealed regularities and features of influence of physical qualities on efficiency of competitive activity testify to expediency of their account: in system of sports selection; in the control of sports fitness; in the prevention of adverse changes; in the optimization of the training process.

\section{Conflicts of Interest}

The authors declare no conflict of interest.

\section{References}

1. Bartlett JD, O'Connor F, Pitchford N, Torres-Ronda L, Robertson SJ. Relationships Between Internal and External Training Load in Team-Sport Athletes: Evidence for an Individualized Approach. International Journal of Sports Physiology and Performance. 2017;12(2):230-234. https://doi.org/10.1123/ijspp.2015-0791

2. Vanrenterghem J, Nedergaard NJ, Robinson MA, Drust B. Training Load Monitoring in Team Sports:ANovel Framework Separating PhysiologicalandBiomechanicalLoad-Adaptation Pathways. Sports Medicine. 2017;47(11):2135-2142. https://doi.org/10.1007/s40279-017-0714-2

3. Platonov VN. The system of training athletes in Olympic sports. General theory and its practical applications. Book 2. Kiev: Olympic literature; 2015. (In Russian).

4. Schneider C, Hanakam F, Wiewelhove T, Doweling A, Kellmann M, Meyer T, et al. Heart Rate Monitoring in Team Sports - A Conceptual Framework for Contextualizing Heart Rate Measures for Training and Recovery Prescription. Frontiers in Physiology. 2018;9. https://doi.org/10.3389/fphys.2018.00639

5. Domanska-Senderowska D, Laguette MJN, Jegier A, Cieszczyk P, September AV, Brzezianska-Lasota E. MicroRNA Profile and Adaptive Response to Exercise Training: A Review. International Journal of Sports Medicine. 2019;40(4):227-235. https://doi.org/10.1055/a-0824-4813

6. Kostiukov VV, Nirka VV. Beach volleyball (pedagogical, biomedical and psychological support for the training of athletes). Moscow: Russian Volleyball Federation; 2011. (In Russian).

7. Natali S, Ferioli D, La Torre A, Bonato M. Physical and technical demands of elite beach volleyball according to playing position and gender. Journal of Sports Medicine and Physical Fitness. 2019;59(1):6-9. https://doi.org/10.23736/s0022-4707.17.07972-5

8. Pelzer T, Schmidt M, Jaitner T, Pfeiffer M. External training load and the effects on training response following three different training sessions in young elite beach volleyball players. International Journal of Sports Science \& Coaching. 2020;15(5-6):717-727. https://doi.org/10.1177/1747954120940488

9. Simac M, Grgantov Z, Milic M. Situational efficacy of top croatian senior beach volleyball players. Acta Kinesiologica. 2017;11(2):35-39.

10.Sanchez M, Gonzalez-Silva J, Fernandez-Echeverria C, Claver F, Moreno MP. Participation and influence of the libero in recepcion and defence, in U-19 volleyball. Revista Internacional De Medicina Y Ciencias De La Actividad Fisica Y Del Deporte. 2019;19(73):45-62. https://doi.org/10.15366/rimcafd2019.73.004

11. Yu YH, Garcia-De-Alcaraz A, Wang LY, Liu TB. Analysis of winningdeterminantperformanceindicatorsaccording toteams level in Chinese women's volleyball. International Journal of Performance Analysis in Sport. 2018;18(5):750-763. https://doi.org/10.1080/24748668.2018.1517289
12.Gilgien $\mathrm{M}, \quad$ Reid $\mathrm{R}$, Raschner $\mathrm{C}, \quad$ Supej M, Holmberg HC. The Training of Olympic Alpine Ski Racers. Frontiers in Physiology. 2018;9. https://doi.org/10.3389/fphys.2018.01772

13.Golovachev AI, Kolykhmatov VI, Shirokova SV. Model indicators of physical preparedness of elite female skiracers in preparation for the 2022 winter olympic games in Beijing (China). Human Sport Medicine. 2019;19:81-87. https://doi.org/10.14529/hsm19s211

14.PrzybylskiP,JaniakA,SzewczykP, WielinskiD, Domaszewska K. Morphological and Motor Fitness Determinants of Shotokan Karate Performance. International Journal of Environmental Research and Public Health. 2021;18(9). https://doi.org/10.3390/ijerph18094423

15.Balasas DG, Christoulas K, Stefanidis P, Vamvakoudis E, Bampouras TM. The effect of beach volleyball training on muscle performance of indoor volleyball players. Journal of Sports MedicineandPhysical Fitness. 2018;58(9):1240-1246. https://doi.org/10.23736/s0022-4707.17.07162-6

16.Casals C, Huertas JR, Franchini E, SterkowiczPrzybycien K, Sterkowicz S, Gutierrez-Garcia C, et al. Special judo fitness test level and anthropometric profile of elite Spanish judo athletes. Journal of Strength and Conditioning Research. 2017;31(5):1229-1235. https://doi.org/10.1519/jsc.0000000000001261

17.Cieslinski I, Gierczuk D, Sadowski J. Identification of success factors in elite wrestlersAn exploratory study. Plos One. 2021;16(3). https://doi.org/10.1371/journal.pone.0247565

18.Kostiukov VV. Beach volleyball (training, technique, tactics). Krasnodar; 2007. (In Russian).

19.Moir GL. Three Different Methods of Calculating Vertical Jump Height from Force Platform Data in Men and Women. Measurement in Physical Education and Exercise Science, 2008;12:207-18. https://doi.org/10.1080/10913670802349766

20.Solovey OM, Hunchenko VV. Analysis of the effectiveness of the results of competitive beach volleyball activities. Sportyvniy visnyk Pridniprovia. 2018;3:126-130. (In Ukrainian).

21.Shankulov Yerlan, Andrusyshyn Iosif, Zaurenbekov Bauyrzhan, Zhunisbek Dinara, Akhmetkarim Marts. Planning efficiency of athletic preparations of highly qualified volleyball players in annual macro-cycle. Journal of Physical Education and Sport, 2020; 20(1): 262-266.

22.Hemberg S, Papageorgiu A. Beach volleyball. Moscow: Terra-Sport; 2004. (In Russian).

23.Fernandez-Echeverria C, Mesquita I, Gonzalez-Silva J, Claver F, Moreno MP. Match analysis within the coaching process: a critical tool to improve coach efficacy. International Journal of Performance Analysis in Sport. 2017;17(1-2):149-163. https://doi.org/10.1080/24748668.2017.1304073

24.Fernandez-Echeverria C, Mesquita I, Gonzalez-Silva J, Moreno MP. Towards a More Efficient Training Process in High-Level Female Volleyball From a Match Analysis Intervention Program Based on the Constraint-Led Approach: 
The Voice of the Players. Frontiers in Psychology. 2021;12. https://doi.org/10.3389/fpsyg.2021.645536

25.Giatsis G. The effect of changing the rules on score fluctuation and match duration in the FIVB women's beach volleyball. International Journal of Performance Analysis in Sport, 2003;3:57-64. https://doi.org/10.1080/24748668.2003.11868275

26.D'Elia F, Sgro F, D'Isanto T. The educational value of the rules in volleyball. Journal of Human Sport and Exercise. 2020;15:S628-S633. https://doi.org/10.14198/jhse.2020.15.Proc3.15

27.Garcia-de-Alcaraz A, Gomez-Ruano MA, Papadopoulou SD. In Search For Volleyball Entertainment: Impact of New Game Rules on Score and Time-Related Variables. Journal of Human Kinetics. 2019;70(1):275-285. https://doi.org/10.2478/hukin-2019-0046

28.Drikos S, Kountouris P, Laios A, Laios Y. Correlates of Team Performance in Volleyball. International Journal of Performance Analysis in Sport, 2009;9:149-56. https://doi.org/10.1080/24748668.2009.11868472

29.Araújo RM, Castro J, Marcelino R, Mesquita IR. Relationship between the Opponent Block and the Hitter in Elite Male Volleyball. Journal of Quantitative Analysis in Sports, 2010;6. https://doi.org/10.2202/1559-0410.1216

30.Silva M, Lacerda D, João PV. Game-Related Volleyball Skills that Influence Victory. Journal of Human Kinetics, 2014;41:173-9. https://doi.org/10.2478/hukin-2014-0045

31.Medeiros AIA, Palao JM, Marcelino R, Mesquita I. Systematic review of sports performance in beach volleyball based on game analysis. Rev Bras Cineantropom Desempenho Hum, 2014;16:698. https://doi.org/10.5007/1980-0037.2014v16n6p698

32.Balasas DG, Christoulas K, Stefanidis P, Vamvakoudis E, Bampouras TM. The effect of beach volleyball training on muscle performance of indoor volleyball players. $J$ Sports Med Phys Fitness, 2018;58. https://doi.org/10.23736/S0022-4707.17.07162-6

33.Lin K (Kyle). Applying Game Theory to Volleyball Strategy. International Journal of Performance Analysis in Sport, 2014;14:761-74. https://doi.org/10.1080/24748668.2014.11868756

34.Hunchenko VV. Serves efficiency as a significant factor in competitive activity in beach volleyball. Physical education, sports and health of the nation, 2018;258:122-9. https://doi.org/10.31652/2071-5285-2018-6-25-122-129

35.Hunchenko VV. The effectiveness of attacking strikes as a determinant of competitive activity in beach volleyball. Sportyvniy visnyk Pridniprovia, 2019;1:3-2. (In Ukrainian).

36. Hunchenko VV. The quality of ball reception as a factor influencing the level of performance of the set and the result of competitive activities in beach volleyball. Actual scientific research in the scientific world, 2019;5(49):16-24. (In Ukrainian).

37.Balasas DG, Christoulas K, Stefanidis P, Vamvakoudis E, Bampouras TM. The effect of beach volleyball training on muscle performance of indoor volleyball players. $J$ Sports Med Phys Fitness, 2018;58. https://doi.org/10.23736/S0022-4707.17.07162-6

38.Koch C, Tilp M. Beach volleyball techniques and tactics. Kinesiology, 2009;1:52-59.

39. Giatsis G, Schrapf N, Koraimann T, Tilp M. Analysis of the arm swing technique during the spike attack in elite beach volleyball. International Journal of Performance Analysis in Sport. 2019;19(3):370-380. https://doi.org/10.1080/24748668.2019.1611291

40.Palao JM, Martinez AL, Valades D, Hernandez E. Manner of Execution and Efficacy of Reception in Men's Beach Volleyball. Montenegrin Journal of Sports Science and Medicine. 2019;8(2):21-26. https://doi.org/10.26773/mjssm.190903

41.Timoshchenko OV. The value of strength and accuracy of movements for competitive activities in various sports. Naukovij chasopis NPU im M.P. Dragomanova, 2016;3:186190. (In Ukrainian).

42.Zemkova E, Vilman T, Cepkova A, Uvacek M, Olej P, Simonek J.Enhancement of powerin the concentric phase of the squat and jump: Between-athlete differences and sport-specific patterns. Journal of Human Sport and Exercise. 2017;12(1):29-40. https://doi.org/10.14198/jhse.2017.121.03

43.Trajkovic N, Kristicevic T, Sporis G. Small-sided games vs. instructional training for improving skill accuracy in young female volleyball players. Acta Kinesiologica. 2017;11(2):72-76.

44.Lehnert M, Sigmund M, Lipinska P, Varekova R, Hroch M, Xaverova $Z$, et al. Training-induced changes in physical performance can be achieved without body mass reduction after eight week of strength and injury prevention oriented programme in volleyball female players. Biology of Sport. 2017;34(2):205-213. https://doi.org/10.5114/biolsport.2017.65995

45. Ramos A, Coutinho P, Silva P, Davids K, Mesquita I. How players exploit variability and regularity of game actions in female volleyball teams. European Journal of Sport Science. 2017;17(4):473-481. https://doi.org/10.1080/17461391.2016.1271459

46.Nikolaidis P, Gkoudas K, Afonso J, Clemente-Suarez VJ, Knechtle B, Kasabalis S, et al. Who jumps the highest? Anthropometric and physiological correlations of vertical jump in youth elite female volleyball players. Journal of Sports Medicine and Physical Fitness. 2017;57(6):802-810. https://doi.org/10.23736/s0022-4707.16.06298-8

47.Tili M, Giatsis G. The height of the men's winners FIVB Beach Volleyball in relation to specialization and court dimensions. Jhse, 2011;6:504-10. https://doi.org/10.4100/jhse.2011.63.04

48. Wnorowski K, Ciemiński K. Volleyball players' somatic composition in the light of sports results at 2014 FIVB Volleyball Men's World Championship. Baltic Journal of Health and Physical Activity, 2016;8:24-31. https://doi.org/10.29359/BJHPA.08.4.03

49.Barzouka K, Sotiropoulos K, Drikos S, Kitsiou A, Angelonidis Y.Current trends of the serve skill in relation to the in-gameroles of the elite volleyball players: Comparison between genders. Journal of Human Sport and Exercise. 2021;16(2):317-331. https://doi.org/10.14198/jhse.2021.162.08

50.Link D, Wenninger S. Performance Streaks in Elite Beach Volleyball - Does Failure in One Sideout Affect Attacking in the Next? Frontiers in Psychology. 2019;10. https://doi.org/10.3389/fpsyg.2019.00919

51.Beach volleyball. Kiev: Brovary printing house; 2003. (In Ukrainian).

52.Hunchenko VV. Training device for practicing practical ball skills. Ukraine Patent 148520. 2021-08-18. p. 5. [cited 2021 Jun 28]. 5 p. Available from: https://base.uipv.org/ searchINV/search.php?action=viewdetails \&IdClaim $=27766$ $1 \&$ chapter=description (In Ukrainian). 


\section{Information about the authors:}

Valeriy Hunchenko; https://orcid.org/0000-0002-1986-1068, altair66v@gmail.com; Prydniprovsk State Academy of Physical Culture and Sports; Naberezhna Pobedy str., 10, Dnieper, 49010, Ukraine.

Oleksandr Solovey; (Corresponding Author); https://orcid.org/0000-0001-8480-2323; 1Soloveyaleksandr@gmail.com; Prydniprovsk State Academy of Physical Culture and Sports; Naberezhna Pobedy str., 10, Dnieper, 49010, Ukraine.

Dmytro Solovey; https://orcid.org/0000-0001-8105-2061; 1Soloveydmitriy@gmail.com; Department of Sports Games; Prydniprovsk State Academy of Physical Culture and Sports; Naberezhna Pobedy str., 10, Dnieper, 49010, Ukraine.

Yaroslav Malojvan; https://orcid.org/0000-0002-6026-5057; malojvanyaroslav@ukr.net; Department of Sports Games; Prydniprovsk State Academy of Physical Culture and Sports; Honored Coach of Ukraine in volleyball; Naberezhna Pobedy str., 10, Dnieper, 49010, Ukraine.

Artem Yakovenko; https://orcid.org/0000-0003-0338-8437; yakovenkoartem2012@gmail.com; Department of Sports Games; Prydniprovsk State Academy of Physical Culture and Sports; Naberezhna Pobedy str., 10, Dnieper, 49010, Ukraine.

Krzysztof Wnorowski; https://orcid.org/0000-0001-5505-7985; krzysztof.wnorowski@awf.gda.pl; Department of Sports, Gdansk University of Physical Education and Sport; Gdansk, Poland.

\section{Cite this article as:}

Hunchenko V, Solovey O, Solovey D, Malojvan Y, Yakovenko A, Wnorowski K. The influence of special physical fitness of athletes on the level of technique of playing beach volleyball. Physical Education of Students, 2021;25(6):364-373. https://doi.org/10.15561/20755279.2021.0605

This is an Open Access article distributed under the terms of the Creative Commons Attribution License, which permits unrestricted use, distribution, and reproduction in any medium, provided the original work is properly cited http://creativecommons.org/licenses/by/4.0/deed.en

Received: 01.10.2021

Accepted: 18.11.2021; Published: 30.12.2021 